\title{
Jak-Stat Signaling Pathway Related Gene Expressions and Blood Biochemical Indicators in Acute Promyelocytic Leukemia
}

\author{
Bui Kieu Trang ${ }^{1}$, Nguyen Thi Xuan ${ }^{1,2, *}$ \\ ${ }^{I}$ Institute of Genome Research, Vietnam Academy of Science and Technology, \\ A17 Building, 18 Hoang Quoc Viet, Cau Giay, Hanoi, Vietnam \\ ${ }^{2}$ Graduate University of Science and Technology, Vietnam Academy of Science and Technology, \\ A28 Building, 18 Hoang Quoc Viet, Cau Giay, Hanoi, Vietnam \\ Received 12 December 2019 \\ Revised 25 February 2020; Accepted 20 March 2020
}

\begin{abstract}
Acute promyelocytic leukemia (APL), caused by a specific (15 and 17) chromosomal translocation, resulting in a fusion gene PML/RAR $\alpha$, is a type of acute leukemia, which has the highest death rate among blood cancers. Klotho gene is important in preventing aging, inflammation and cancer. CTLA4, PD1 and LAG3, immunosuppressive receptors located on the surface of $\mathrm{T}$ cells, are considered as a negative regulation of immune response. These genes regulate immune cell activity through several signalling moleculars such as STATs and NF- $\mathrm{B}$. This study measures mRNA expression of the named genes by using realtime-PCR to determine the difference between APL and other leukemia. The study results show that mRNA levels of $K L$, CTLA4, PD1 and LAG3 genes were lower, while the expressions of STAT1, STAT3, STAT5 and STAT6 genes were significantly higher in the APL patients than in the healthy controls. In addition, $I \kappa B-\alpha$ gene expression was unaltered on APL cells. These results are expected to partially contribute to a better understanding of the differences in JAK-STAT signaling associated gene expressions between APL and other leukemia groups. This is important in applying effective chemotherapy for each type of leukemia.
\end{abstract}

Keywords: Acute promyelocytic leukemia, klotho, CTLA4, IкB- $\alpha$, LAG3, PD1, STAT.

\footnotetext{
* Corresponding author.

E-mail address: xuannt@igr.ac.vn
}

https://doi.org/10.25073/2588-1132/vnumps.4197 


\title{
Biểu hiện một số gen liên quan đến tín hiệu Jak-Stat và chỉ số sinh hóa máu trên bệnh bạch cầu tiền tủy bào
}

\author{
Bùi Kiều Trang ${ }^{1}$, Nguyễn Thị Xuân ${ }^{1,2, *}$ \\ ${ }^{1}$ Viện Nghiên cưu hệ gen, Viện Hàn lâm Khoa học và Công nghệ Việt Nam \\ Nhà A17, 18 Hoàng Quốc Việt, Cầu Giấy, Hà Nội, Việt Nam \\ ${ }^{2}$ Học viện Khoa hoc và Công nghệ, Viện Hàn lâm Khoa học và Công nghệ Việt Nam \\ Nhà A28, 18 Hoàng Quốc Việt, Cầu Giấy, Hà Nội, Việt Nam \\ Nhận ngày 12 tháng 12 năm 2019 \\ Chỉnh sửa ngày 25 tháng 02 năm 2020; Chấp nhận đăng ngày 20 tháng 3 năm 2020
}

\begin{abstract}
Tóm tắt: Bạch cầu cấp dạng tiền tủy bào (APL) là một loại bệnh bạch cầu cấp tính gây tử vong cao nhất trong số bệnh ung thư máu và được gây ra do hoạt động chuyển vị của nhiễm sắc thể 15 và 17 tạo ra tổ hợp gen $P M L / R A R-\alpha$. Gen klotho $(K L)$ có vai trò ngăn chặn sự lão hóa, phản ứng viêm và ung thư. CTLA4, PD1 và LAG3 là những thụ thể kiểm soát miển dịch nằm trên bề mặt của tế bào $T$ và có vai trò điều hòa ngược phản ứng miễn dịch. Các gen trên điều hòa hoạt động tế bào miễn dịch thông qua một số tín hiệu phân tử như STAT và NF-kB. Trong nghiên cứu này, để củng cố thêm sự khác biệt giữa bệnh APL với bệnh bạch cầu khác, chúng tôi tiến hành đo mức độ biểu hiện mRNA của các gen trên bằng kỹ thuật realtime-PCR. Kết quả nhận được cho thấy mức độ biểu hiện mRNA của gen $K L, C T L A 4, P D 1$ và $L A G 3$ thấp hơn, trong khi nhóm gen STAT1, STAT3, STAT5 và STAT6 có mức độ biểu hiện cao hơn rõ rệt ở bệnh nhân APL so với người khỏe mạnh. Ngoài ra, biểu hiện gen $I \kappa B-\alpha$ không thay đổi trên tế bào APL. Kết quả nghiên cứu đóng góp một phần hiểu biết về sự khác biệt biểu hiện gen liên quan đến tín hiệu JAK-STAT giữa bệnh APL với nhóm bệnh bạch cẩu khác. Điều này có ý nghĩa quan trọng trong ứng dụng liệu pháp hóa trị hiệu quả cho từng loại bệnh bạch cầu.
\end{abstract}

Từ khóa: Bạch cầu tiền tủy bào, klotho, CTLA4, IкB- $\alpha$, LAG3, PD1, STAT.

\section{1. Đặt vấn đề}

Bệnh bạch cầu cấp tính dạng tiền tủy bào (acute promyelocytic leukemia-APL) là một

\footnotetext{
*Tác giả liên hệ.

Địa chi email: xuannt@igr.ac.vn
}

https://doi.org/10.25073/2588-1132/vnumps.4197 phân nhóm của bệnh bạch cầu cấp tính dòng tủy (AML) gây ra bởi sự chuyển vị của nhiễm sắc thể 15 và 17 tạo ra một bản sao hợp nhất giữa các gen $P M L$ và $R A R-\alpha$ được ký hiệu là t $(15$; 17) $(\mathrm{q} 22 ; \mathrm{q} 21)[1,2]$. Các tiền tủy bào cần thời gian ngắn hơn bình thường để tăng sinh số lượng trong tủy xương bệnh nhân [2]. Bệnh chiếm khoảng $15-20 \%$ trong số các bệnh $\mathrm{AML}$ 
và gần như $100 \%$ tử vong sớm do các rối loạn đông máu và không có các biện pháp điều trị đặc hiệu [2].

Có nhiều nghiên cứu về đa hình và biểu hiện gen có chức năng điều hòa hoạt động hệ miễn dịch trên bệnh nhân ung thư. Một trong những gen được nghiên cứu rộng rãi là gen klotho [3]. Gen này có vai trò quan trọng ngăn chặn lão hóa, phản ứng viêm và ung thư. Chuột đột biến gen $K L$ dẫn đến chức năng của gen này bi bất hoạt, gây ra hiện tượng lão hóa sớm từ khi chuột sinh ra và chết sau khoảng 2-3 tháng do sự tích tụ quá nhiều canxi trong các khớp xương, mạch máu và các bệnh về tim mạch và tự miê̂n dịch [3]. Quá trình lão hóa liên quan đến sự gián đoạn quá trình tạo máu gây thiếu máu, hình thành các khối u ác tính và phát triển thành bệnh bạch cầu $[4,5]$. Gen $K L$ không biểu hiện trên tế bào ung thư bạch cầu tủy mạn tính [6]. Một số nghiên cứu khác chỉ ra mối tương quan giữa biểu hiện gen $K L$ với hoạt động sinh lý của kênh ion như kênh $\mathrm{Ca}^{2+}$ trên tế bào miễn dịch, từ đó ứng dụng tăng cường miễn dịch chống lại bệnh thông qua việc cung cấp thêm các nguyên tố khoáng phù hợp kết hợp với điều trị gen đích $[4,5]$.

Ngoài gen $K L$, một số gen có vai trò kiểm soát hệ miễn dịch gồm $C T L A 4, P D 1$ và $L A G 3$ cũng được tập trung nghiên cứu và ứng dụng trong điều trị ung thư bằng liệu pháp gen đích sử dụng các loại kháng thể hoặc thuốc ức chế biểu hiện. CTLA4, PD1 và LAG3 là những thụ thể kiểm soát miễn dịch nằm trên bề mặt của tế bào $\mathrm{T}$ và có vai trò điều hòa ngược phản ứng miễn dịch [7-9]. CTLA4 điều hòa hoạt động của các tế bào T thông qua ức chế tín hiệu phân tử CD28-CD80/CD86 [7]. PD1 điều hòa hoạt động của tế bào $\mathrm{T}$ chủ yếu ở các vùng ngoại vi [8]. LAG3 được tìm thấy trên các tế bào $\mathrm{T}$ điều hòa trong nhiều loại ung thư [9]. Ở người, LAG3 biểu hiện đồng thời với PD1 gây ra một trạng thái kiệt sức cho tế bào T. Protein LAG3 liên kết với phân tử MHC-II làm giảm khả năng miễn dịch chống ung thư bằng cách ức chế sự tiết IFN- $\gamma$ của các tế bào $\mathrm{T}[10,11]$. LAG3 biểu hiện cao ở các bệnh nhân mắc bệnh bạch cầu lympho mạn không đáp ứng điều trị [12].
Song song với các nghiên cứu về biểu hiện gen chức năng, các khảo sát về gen tín hiệu tham gia kiểm soát chức năng sinh lý tế bào cũng được chú trọng. Có nhiều nghiên cứu về nhóm gen STAT điều hòa các phản ứng miễn dịch trên cơ thể người bệnh như sự tiết cytokine, sự tăng sinh, biệt hóa, di cư và sự chết apoptosis của tế bào. Sự biểu hiện bất thường của tín hiệu STAT dẫn tới phát triển bệnh bạch cầu $[1,13,14]$. Kích hoạt protein STAT đặc biệt là STAT3 và STAT5 liên quan đến sự chuyển đổi hình thái và chức năng tế bào ung thư [15]. Ngoài gen STAT, biểu hiện gen IkB- $\alpha$ đã được chứng minh là đóng vai trò quan trọng trong các loại ung thư máu khác nhau [16]. Gen này có chức năng ức chế yếu tố phiên mã $\mathrm{NF}-\kappa \mathrm{B}$ và sự giáng hóa IkB- $\alpha$ gây ra sự hoạt hóa $\mathrm{NF}-\kappa \mathrm{B}$ trong tế bào [17].

Các nghiên cứu về biểu hiện các gen này trên bệnh nhân APL người Việt Nam chưa được chú trọng. Trong nghiên cứu này, chúng tôi tiển hành tách chiết RNA tổng số từ các mẫu máu và xác định mức độ biểu biện một số gen $K L$, CTLA4, PD1, LAG3, STAT1, STAT3, STAT5, $S T A T 6$ và $I \kappa B-\alpha$ trên bệnh nhân APL phục vụ cho công tác chẩn đoán và điều trị bệnh hiệu quả.

\section{Vật liệu và phương pháp nghiên cứu}

\section{1. Đối tượng nghiên cưu}

Tại Bệnh viện Huyết học và Truyền máu Trung ương và Bệnh viện Quân Y 103, Hà Nội, Việt Nam, mẫu máu ngoại vi được thu thập từ 13 bệnh nhân chưa được điều trị được chẩn đoán mắc bệnh APL. Các bệnh nhân đã được thăm khám lâm sàng, làm các xét nghiệm cận lâm sàng và giải phẫu bệnh để chẩn đoán xác định từng loại bệnh.

Nhóm đối chứng gồm 10 người khỏe mạnh, trong đó không có cá nhân nào đang dùng thuốc hoặc bị bất kỳ bệnh cấp tính hay mãn tĩnh nào khác. Tất cả bệnh nhân và tình nguyện viên đã ký văn bản đồng ý tham gia nghiên cứu. Các quy trình thí nghiệm và việc chăm sóc từng cá nhân được thực hiện theo luật pháp Việt Nam và đã được phê duyệt bởi Hội đồng $\mathrm{Y}$ Đức của 
Viện nghiên cứu hệ gen, Viện Hàn lâm Khoa học và Công Nghệ Việt Nam.

\subsection{Phuơng pháp nghiên cúu}

Tách chiết RNA tổng số và phân tích mức độ biểu hiện gen bằng kỹ thuật Realtime-PCR.

Tổng lượng RNA được tách chiết bằng Trizol theo hướng dẫn của hãng Invitrogen. cDNA được tổng hợp từ RNA tổng số theo quy trình như sau: lấy $1 \mu \mathrm{g}$ RNA tổng số pha loãng vào nước cất $\mathrm{DEPC}$ thành $12,5 \mu \mathrm{l}$. Sau đó, thêm $1 \mu 1$ oligo-dT primer $(500 \mu \mathrm{g} / \mathrm{ml}$, Invitrogen $)$ và ủ ở nhiệt độ $70^{\circ} \mathrm{C}$ trong 2 phút. Cho thêm vào ống đựng mẫu $2 \mu 1 \quad 10 \mathrm{x}$ reaction buffer (Biolabs), $1 \mu \mathrm{l}$ dNTP mix (dATP, dCTP, dGTP, dTTP, $10 \mathrm{mM}$ mỗi loại), $0,5 \mu 1$ chất ức chế Rnase (Roche), $0,1 \mu 1$ enzyme phiên mã ngược M-MuLV (Biolabs) và $2,9 \mu 1$ nước cất DEPC. Trộn đều mẫu sau đó ủ ở $42^{\circ} \mathrm{C}$ trong 1 tiếng. Để dừng phản ứng tổng hợp cDNA, các mẫu được ủ ở $94^{\circ} \mathrm{C}$ trong 5 phút và dự trữ ở $-80^{\circ} \mathrm{C}$. Mẫu cDNA được phân tích mức độ biểu hiện các gen CTLA-4, PD-1, LAG-3, KL, STAT-1, STAT-3, STAT-5, STAT-6, I $K$ - $\alpha$ và $G A P D H$. Các primer được sử dụng bao gồm:

\begin{tabular}{ll}
\hline Tên mồi & Trình tự nucleotide \\
\hline CTLA4_F & 5'GTCCGGGTGACAGTGCTTCG3' \\
CTLA4_R & 5'CCAGGTAGTATGGCGGTGGG3' \\
PD-1_F & 5'TGCAGCTTCTCCAACACATC3' \\
PD-1_R & 5'CACGCTCATGTGGAAGTCAC3' \\
LAG-3_F & 5'CCTCACTGTTCTGGGTCTGG' \\
LAG-3_R & 5'GGATATGGCAGGTGTAGGTC3' \\
Klotho_F & 5''CTAAGCCAGGACAAGATG3' \\
Klotho_R & 5'TCAGGTCGGTAAACTGAG3' \\
STAT-1_F & 5'CCCTTCTGGCTTTGGATTGAA3' \\
STAT-1_R & 5'CTTCCCGGGAGCTCTCACTGA3' \\
STAT-3_F & 5'GGAGGAGTTGCAGCAAAAAG3' \\
STAT-3_R & 5'TGTGTTTGTGCCCAGAATGT3' \\
STAT-5_F & 5'CAGACCAAGTTTGCAGCCAC3' \\
STAT-5_R & 5'CACAGCACTTTGTCAGGCAC3' \\
STAT-6_F & 5'GCCCACTCACTCCAGAGGACCT3' \\
STAT-6_R & 5'GGTGTTGGGGAAAGTCGACAT3' \\
IkB- $\alpha$ F & 5'GCAAAATCCTGACCTGGTGT3' \\
IkB- $\alpha$ R & 5'GCTCGTCCTCTGTGAACTCC3' \\
GAPDH_F & 5'GGAGCGAGATCCCTCCAAA3' \\
GAPDH_R & 5'GGCTGTTGTCATACTTCTCAT3' \\
\hline
\end{tabular}

Phản ứng quantitative PCR chứa $20 \mu 1$ tổng thể tích gồm $2 \mu 1 \mathrm{cDNA}, 2.4 \mu 1 \mathrm{MgCl} 2(3 \mu \mathrm{M})$, $1 \mu 102$ loại primer $(0.5 \mu \mathrm{M}$ mỗi loại $), 2 \mu 1$ cDNA Master SybrGreen I mix (Roche Molecular Biochemicals) và $12.6 \mu \mathrm{l}$ nước DEPC. Đoạn cDNA được khuếch đại ở $95^{\circ} \mathrm{C}$ trong 10 giây, $62^{\circ} \mathrm{C}$ trong 10 giây, and $72^{\circ} \mathrm{C}$ trong 16 giây, số vòng nhắc lại là 40 vòng. Phương pháp RT-PCR định lượng cho SHP-1 và SHP-2 được thực hiện trên hệ thống LightCycler System (Roche Diagnostics). Tỷ lệ biểu hiện tương quan giữa các gen nghiên cứu và gen GAPDH đối chứng được tính trên mỗi mẫu theo phương pháp ngưỡng chu trình.

\subsection{Phương pháp xử lý số liệu}

Kết quả thí nghiệm là trung bình cộng của các giá trị và được xử lý bằng phương pháp ANOVA. Các nghiên cứu được lặp lại ít nhất 3 lần. Sự khác biệt giữa mẫu đối chứng và mẫu bệnh nhân có ý nghĩa thống kê khi chỉ số $\mathrm{p}$ value $<0.05$.

\section{Kết quả và thảo luận}

Chỉ số xét nghiệm sinh hóa máu bệnh nhân APL.

Kết quả xét nghiệm sinh hóa máu chỉ ra rằng tỷ lệ $\mathrm{BN} \mathrm{APL}$ có chỉ số glucose, axid uric, protein toàn phần, globulin, ferritin, AST, ALT và lactate dehydrogenase $(\mathrm{LDH})$ cao hơn người khỏe mạnh tương ứng là $15.4 \%, 15.4 \%, 46.1 \%$, $46.1 \%, 38.5 \%, 30.8 \%, 38.5 \%$ và $23.1 \%$ (Bảng 1). Nồng độ các chỉ số sinh học này tăng cao chỉ ra mức độ ảnh hưởng cao của bệnh đến sự tổn thương các cơ quan thận, gan và một số cơ quan khác. Nồng độ LDH tăng cao dẫn đến tăng nồng độ lactat trong máu và tổn thương mô. Ngoài ra, các chỉ số hóa sinh khác như bilirubin và định lượng sắt huyết thanh cũng có một số $\mathrm{BN}$ có các chỉ số này cao hơn bình thường. 
Bảng 1. Tỷ lệ BN APL có chỉ số xét nghiệm sinh hóa máu cao hơn bình thường

\begin{tabular}{llll}
\hline STT & Chỉ số bệnh & $\begin{array}{l}\text { Bệnh } \\
\text { nhân }(\mathrm{n})\end{array}$ & $\begin{array}{l}\text { Bệnh } \\
\text { nhân }(\%)\end{array}$ \\
\hline 1 & Ure & $0 / 13$ & 0.0 \\
2 & Glucose & $2 / 13$ & 15.4 \\
3 & Creatinin & $0 / 13$ & 0.0 \\
4 & Axid uric & $2 / 13$ & 15.4 \\
& Bilirubin toàn & $1 / 13$ & 7.7 \\
5 & phần & $6 / 13$ & 46.1 \\
6 & Protein toàn phần & 0.0 \\
7 & Albumin & $0 / 13$ & 0.0 \\
8 & Globulin & $6 / 13$ & 46.1 \\
9 & chỉ số A/G & $0 / 13$ & 0.0 \\
10 & Ferritin & $5 / 13$ & 38.5 \\
11 & Calci ion hóa & $0 / 13$ & 0.0 \\
12 & AST (GOT) & $4 / 13$ & 30.8 \\
13 & ALT (GPT) & $5 / 13$ & 38.5 \\
14 & LDH & $3 / 13$ & 23.1 \\
15 & Canxi toàn phần & $0 / 13$ & 0.0 \\
& Định lượng sắt & $1 / 13$ & 7.7 \\
16 & huyết thanh & & 0.0 \\
17 & Na+ & $0 / 13$ & 0.0 \\
18 & K+ & $0 / 13$ & 0.0 \\
19 & Cl- & $0 / 13$ &
\end{tabular}

Mức độ biểu hiện của gen KL, CTLA4, PD1 và LAG3.
Nhóm gen kiểm soát miễn dịch CTLA4, $P D 1$ và $L A G 3$ biểu hiện cao trên tế bào $\mathrm{T}$, đặc biệt là tế bào $\mathrm{T}$ điều hòa và có vai trò tăng cường hệ miễn dịch đối kháng, chính vì vậy biểu hiện cao của những gen này thuận lợi cho sự tăng sinh của tế bào ung thư [7-9]. Tuy nhiên, trên bệnh nhân APL, chúng tôi không tìm thấy sự khác biệt về biểu hiện của chúng và thậm chí biểu hiện của gen CTLA4 và LAG3 còn hơi giảm so với người khỏe (Hình 1). Mức độ biểu hiện mRNA cao của CTLA4 được chứng minh có liên quan đến thời gian điều trị giai đoạn khởi phát dài hơn trong bệnh bạch cầu lympho mạn tính tế bào $B$ [18] và có tiên lượng kém hơn so với người có biểu hiện thấp $[19$, 20]. Mức độ biểu hiện của gen $P D 1$ ở bệnh nhân bạch cầu lympho mạn tính cũng được chứng minh là cao hơn so với người khỏe mạnh [21]. Theo nghiên cứu của Long L. và cộng sự, gen LAG3 có mức độ biểu hiện cao trong các bệnh nhân mắc các bệnh về máu [22]. Tuy nhiên, biểu hiện gen $L A G 3$ cao trên bệnh nhân ung thư có sự hồi phục tốt hơn so với bệnh nhân khác [23]. Kết quả mức độ biểu hiện của gen CTLA4, PD1 và $L A G 3$ ở bệnh nhân $\mathrm{APL}$ trong nghiên cứu này phản ánh biểu hiện hệ miễn dịch bệnh nhân APL ít liên quan đến hoạt động của miễn dịch đối kháng.
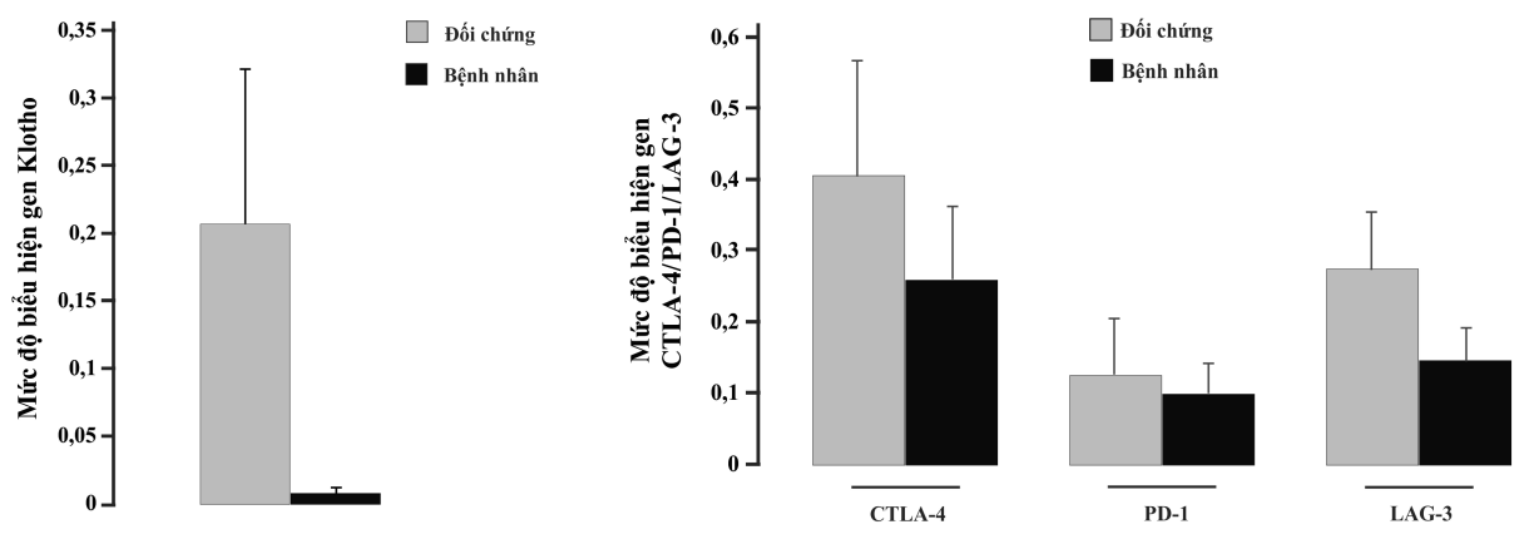

Hình 1. Biểu hiện mRNA của các gen $K L, C T L A 4, P D 1$ và $L A G 3$ trên bệnh nhân APL (cột màu đen) và mẫu đối chứng (cột màu trắng). 
Ngược lại với 03 gen kiểm soát miễn dịch trên, gen $K L$ đã được chứng minh là tham gia ngăn chặn quá trình lão hóa, phản ứng viêm và sự tăng sinh của tế bào ung thư. Biểu hiện của gen này giảm xuống là một trong những nguyên nhân gây ra nhiều loại bệnh ung thư $[4,5]$. Tương tự, nghiên cứu của chúng tôi cũng chỉ ra gen $K L$ có mức độ biểu hiện giảm xuống ở bệnh nhân APL (Hình 1). Một nghiên cứu gần đây đã chỉ ra rằng, biểu hiện gen $K L$ giảm ảnh hưởng đến sự tăng nồng độ của 1,25Dihydroxyvitamin D3 (D3) trong máu, dẫn đến hiện tượng các khớp xương bị vôi hóa sớm, bệnh lão hóa tim mạch và hệ miễn dịch bất hoạt [3]. Tế bào ung thư APL khi tiếp xúc với D3 có biểu hiện hoạt hóa tăng lên dẫn đến sự tăng sinh nhiều hơn so với tế bào không được xử lý [24]. Chính vì vậy, biểu hiện giảm gen $K L$ liên quan một phần đến sự tăng sinh của tế bào APL

Trong nghiên cứu này, chúng tôi đã chỉ ra rằng bệnh nhân $\mathrm{APL}$ có biểu hiện các gen STAT tăng rõ rệt so với người khỏe mạnh và kết quả này có ý nghĩa thống kê, trong khi biểu hiện gen $I \kappa B-\alpha$ không thay đồi trong tế bào APL. Tổng số 04 gen STAT1, STAT3, STAT5 và STAT6 đều tăng trong bệnh nhân APL phản ánh rằng, gen STAT đặc biệt quan trọng điều hòa quá trình gây bệnh APL. Nghiên cứu của chúng tôi là nghiên cứu đầu tiên chỉ ra sự tăng biểu hiện của tổng thể 04 gen, chứng tỏ rằng việc sử dụng thuốc ức chế tyrosine phosphatase trong điều trị bệnh APL hoàn toàn phù hợp. Các nghiên cứu khác trên bệnh nhân ung thư máu cũng phân tích biểu hiện nhóm gen STAT, tuy nhiên chưa có nghiên cứu nào chỉ ra biểu hiện tăng lên của cả 04 gen này trong một bệnh ung thư. Biểu hiện của STAT1 tăng cao trong bệnh bạch cầu bao gồm bệnh APL đã được biết đến trong nhiều nghiên cứu $[1,25]$. Sự kích hoạt tín hiệu STAT3 và STAT5 cũng được chỉ ra ở bệnh $u$ lympho và bệnh bạch cầu [26, 27]. Mức độ biểu hiện gen STAT6 quá mức cũng được tìm thấy trên một số bệnh ung thư máu [28] và tương quan thuận với sự tăng khả năng xâm lấn và di căn của tế bào ung thư [29]. Biểu hiện gen STAT6 tăng cao trên bệnh nhân APL trong nghiên cứu này phản ánh tình trạng nặng của bệnh. Ngoài gen tín hiệu STAT, gen $I \kappa B$ - $\alpha$ cũng được khảo sát trong nghiên cứu này, tuy nhiên biểu hiện của gen này không thay đổi trong tế bào ung thư APL. Khác với bệnh APL, biểu hiện gen $I \kappa B-\alpha$ giảm đi rõ rệt trên một số bệnh bạch cầu khác $[16,30]$. Điều này chỉ ra rằng, mức độ biểu hiện gen $I \kappa B-\alpha$ ở nhóm bệnh nhân APL là khác biệt so với nhóm bệnh bạch cầu còn lại. Xác định sự khác biệt về biểu hiện gen tín hiệu có ý nghĩa quan trọng trong việc điều chỉnh các loại thuốc sử dụng cho liệu pháp hóa trị phù hợp với từng loại bệnh.
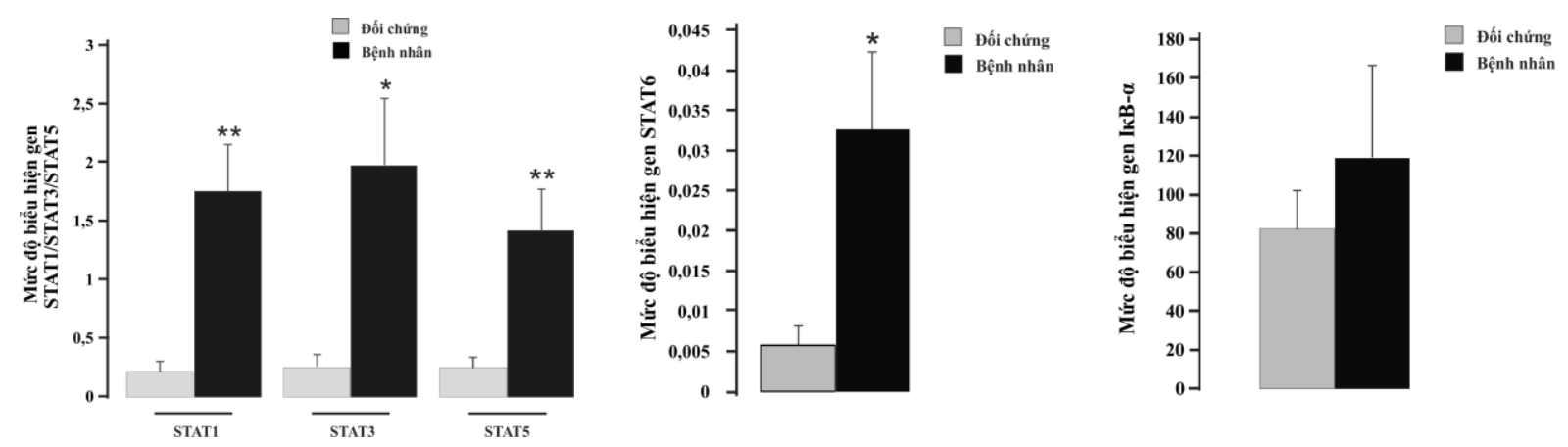

Hình 2. Sản phẩm realtime-PCR các gen STAT1, STAT3, STAT5, STAT6 và IאB- $\alpha$ của các mẫu bệnh nhân $\mathrm{APL}$ (cột màu đen) và mẫu đối chứng (cột màu trắng). ${ }^{*} \mathrm{p}<0.05$ và ** $\mathrm{p}<0.01$ chỉ ra sự khác biệt có ý nghĩa thống kê giữa nhóm đối chứng và nhóm bệnh nhân (ANOVA). 
Bảng 2. So sánh biểu hiện nhóm gen STAT của bệnh nhân APL trên thế giới

\begin{tabular}{|c|c|c|c|c|c|c|c|c|}
\hline \multirow{2}{*}{$\begin{array}{l}\text { Loại } \\
\text { bệnh }\end{array}$} & \multirow[t]{2}{*}{ Địa điểm } & \multirow{2}{*}{$\begin{array}{l}\text { Số } \\
\text { lượng }\end{array}$} & \multirow{2}{*}{$\begin{array}{l}\text { Độ } \\
\text { tuồi }\end{array}$} & \multicolumn{4}{|c|}{ Biểu hiện gen STAT } & \multirow{2}{*}{$\begin{array}{l}\text { Tài liệu tham } \\
\text { khảo }\end{array}$} \\
\hline & & & & $\begin{array}{l}\text { STA } \\
\text { T1 }\end{array}$ & $\begin{array}{l}\text { STAT } \\
3 \\
\end{array}$ & $\begin{array}{l}\text { STAT } \\
5\end{array}$ & $\begin{array}{l}\text { STAT } \\
6 \\
\end{array}$ & \\
\hline \multirow{2}{*}{ APL } & Ý & 5 & & Tăng & & & & [1] \\
\hline & Việt Nam & 37 & $15-70$ & Tăng & Tăng & Tăng & Tăng & Nghiên cứu này \\
\hline \multirow{4}{*}{$\begin{array}{l}\text { Bạch } \\
\text { cầu tủy } \\
\text { cấp }\end{array}$} & Mỹ & & & Tăng & Tăng & Tăng & & [31] \\
\hline & Pháp & 5 & $66-68$ & Tăng & Tăng & Tăng & & [26] \\
\hline & Đức & 14 & & Tăng & Tăng & Tăng & & [27] \\
\hline & Úc & 94 & & & Giảm & & & [13] \\
\hline \multirow{4}{*}{$\begin{array}{l}\text { Bạch } \\
\text { cầu tủy } \\
\text { mạn }\end{array}$} & Đức & & & Giảm & & & & [14] \\
\hline & Mỹ & & & & & Tăng & & [31] \\
\hline & Mỹ & & & & & Tăng & & [32] \\
\hline & Mỹ & & & & & Tăng & & [30] \\
\hline
\end{tabular}

So sánh biểu hiện gen STAT của bệnh nhân APL trên thế giới.

So sánh với một số nước trên thế giới, chúng tôi chỉ ra rằng biểu hiện gen STAT là khác biệt trên mỗi bệnh ung thư máu khác nhau (Bảng 2). Tuy nhiên, biểu hiện 04 gen STATl, STAT3, STAT5 và STAT6 đều tăng trên bệnh nhân APL là một phát hiện mới, chưa được đề cập đến.

\section{Kết luận}

Như vậy, nghiên cứu về mức độ biểu hiện của các gen $K L, C T L A 4, P D 1, L A G 3$, STAT1, STAT3, STAT5, STAT6 và $I \kappa B-\alpha$ trên bệnh nhân APL góp phần hiểu biết thêm về hoạt động của một số gen chức năng và gen tín hiệu kiểm soát hệ miễn dịch trên bệnh nhân APL, trong đó gen STAT6 đặc biệt quan trọng liên quan mật thiết đến tình trạng bệnh nặng. Biểu hiện của 04 gen STAT1, STAT3, STAT5 và STAT6 tăng lên và biểu hiện gen $I \kappa B$ - $\alpha$ không thay đổi chỉ ra vai trò đặc biệt quan trong của nhóm gen STAT điều hòa hoạt động tế bào APL và khác biệt với nhóm bệnh bạch cầu khác. Điều này có ý nghĩa quan trọng trong ứng dụng liệu pháp hóa trị hiệu quả cho từng loại bệnh bạch cầu.

\section{Lời cảm ơn}

Công trình hoàn thành với kinh phí được tài trợ bởi Chương trình phát triển khoa học cơ bản trong lĩnh vực Hóa học, Khoa học sự sống, Khoa học trái đất và Khoa học biển giai đoạn 2017-2025, Bộ Khoa học và Công nghệ.

\section{Tài liệu tham khảo}

[1] M. Gianni, M. Terao, I. Fortino, M. LiCalzi, V. Viggiano, T. Barbui, A. Rambaldi, E. Garattini, Stat 1 is induced and activated by all-trans retinoic acid in acute promyelocytic leukemia cells, Blood, 89 (1997) 1001-1012.

[2] A. Kohlmann, C. Schoch, M. Dugas, S. Rauhut, F. Weninger, S. Schnittger, W. Kern, T. Haferlach, Pattern robustness of diagnostic gene expression signatures in leukemia, Genes, chromosomes \& cancer, 42 (2005) 299-307.

[3] C.B. Leibrock, J. Voelkl, O.M. Kuro, F. Lang, U.E. Lang, 1,25(OH)2D3 dependent overt hyperactivity phenotype in klotho-hypomorphic mice, Scientific reports, 6 (2016) 24879.

[4] D. Skrajnowska, B. Bobrowska-Korczak, A. Tokarz, Disorders of Mechanisms of Calcium Metabolism Control as Potential Risk Factors of Prostate Cancer, Current medicinal chemistry, 24 (2017) 4229-4244. 
[5] V. Delcroix, O. Mauduit, N. Tessier, A. Montillaud, T. Lesluyes, T. Ducret, F. Chibon, F. Van Coppenolle, S. Ducreux, The Role of the Anti-Aging Protein Klotho in IGF-1 Signaling and Reticular Calcium Leak: Impact on the Chemosensitivity of Dedifferentiated Liposarcomas, 10 (2018).

[6] M. Azuma, D. Koyama, J. Kikuchi, H. Yoshizawa, D. Thasinas, K. Shiizaki, M. Kuro-o, Y. Furukawa, E. Kusano, Promoter methylation confers kidney-specific expression of the Klotho gene, FASEB journal : official publication of the Federation of American Societies for Experimental Biology, 26 (2012) 4264-4274.

[7] E.L. Masteller, E. Chuang, A.C. Mullen, S.L. Reiner, C.B. Thompson, Structural analysis of CTLA-4 function in vivo, Journal of immunology (Baltimore, Md. : 1950), 164 (2000) 5319-5327.

[8] B.T. Fife, J.A. Bluestone, Control of peripheral Tcell tolerance and autoimmunity via the CTLA-4 and PD-1 pathways, Immunological reviews, 224 (2008) 166-182.

[9] L.P. Andrews, A.E. Marciscano, C.G. Drake, D.A. Vignali, LAG3 (CD223) as a cancer immunotherapy target, Immunological reviews, 276 (2017) 80-96.

[10] B. Huard, P. Prigent, M. Tournier, D. Bruniquel, F. Triebel, CD4/major histocompatibility complex class II interaction analyzed with CD4- and lymphocyte activation gene-3 (LAG-3)-Ig fusion proteins, European journal of immunology, 25 (1995) 2718-2721.

[11] F. Xu, J. Liu, D. Liu, B. Liu, M. Wang, Z. Hu, X. $\mathrm{Du}$, L. Tang, F. He, LSECtin expressed on melanoma cells promotes tumor progression by inhibiting antitumor T-cell responses, Cancer research, 74 (2014) 3418-3428.

[12] J. Kotaskova, B. Tichy, M. Trbusek, H.S. Francova, J. Kabathova, J. Malcikova, M. Doubek, Y. Brychtova, J. Mayer, S. Pospisilova, High expression of lymphocyte-activation gene 3 (LAG3) in chronic lymphocytic leukemia cells is associated with unmutated immunoglobulin variable heavy chain region (IGHV) gene and reduced treatment-free survival, The Journal of molecular diagnostics: JMD, 12 (2010) 328-334.

[13] P. Aigner, T. Mizutani, J. Horvath, T. Eder, STAT3beta is a tumor suppressor in acute myeloid leukemia, 3 (2019) 1989-2002.

[14] C. Schubert, M. Allhoff, S. Tillmann, T. Maie, I.G. Costa, D.B. Lipka, M. Schemionek, K. Feldberg, J. Baumeister, T.H. Brummendorf, N. Chatain, S. Koschmieder, Differential roles of
STAT1 and STAT2 in the sensitivity of JAK2V617F- vs. BCR-ABL-positive cells to interferon alpha, Journal of hematology \& oncology, 12 (2019) 36.

[15] T. Bowman, R. Garcia, J. Turkson, R. Jove, STATs in oncogenesis, Oncogene, 19 (2000) 2474-2488.

[16] C. Gasparini, C. Celeghini, L. Monasta, G. Zauli, NF-kappaB pathways in hematological malignancies, Cellular and molecular life sciences : CMLS, 71 (2014) 2083-2102.

[17] S. Prasad, J. Ravindran, B.B. Aggarwal, NFkappaB and cancer: how intimate is this relationship, Molecular and cellular biochemistry, 336 (2010) 25-37.

[18] N. Erfani, S.M. Mehrabadi, M.A. Ghayumi, M.R. Haghshenas, Z. Mojtahedi, A. Ghaderi, D. Amani, Increase of regulatory $T$ cells in metastatic stage and CTLA-4 over expression in lymphocytes of patients with non-small cell lung cancer (NSCLC), Lung cancer (Amsterdam, Netherlands), 77 (2012) 306-311.

[19] K.V. Shah, A.J. Chien, C. Yee, R.T. Moon, CTLA-4 is a direct target of Wnt/beta-catenin signaling and is expressed in human melanoma tumors, The Journal of investigative dermatology, 128 (2008) 2870-2879.

[20] S. Salvi, V. Fontana, S. Boccardo, D.F. Merlo, E. Margallo, S. Laurent, A. Morabito, E. Rijavec, M.G. Dal Bello, M. Mora, G.B. Ratto, F. Grossi, M. Truini, M.P. Pistillo, Evaluation of CTLA-4 expression and relevance as a novel prognostic factor in patients with non-small cell lung cancer, Cancer immunology, immunotherapy : CII, 61 (2012) 1463-1472.

[21] M. Grzywnowicz, J. Zaleska, D. Mertens, W. Tomczak, P. Wlasiuk, K. Kosior, A. Piechnik, A. Bojarska-Junak, A. Dmoszynska, K. Giannopoulos, Programmed death-1 and its ligand are novel immunotolerant molecules expressed on leukemic B cells in chronic lymphocytic leukemia, PloS one, 7 (2012) e35178.

[22] L. Long, X. Zhang, F. Chen, Q. Pan, P. Phiphatwatchara, Y. Zeng, H. Chen, The promising immune checkpoint LAG-3: from tumor microenvironment to cancer immunotherapy, Genes \& cancer, 9 (2018) 176189.

[23] R.R. Saleh, P. Peinado, J. Fuentes-Antras, P. Perez-Segura, A. Pandiella, E. Amir, A. Ocana, Prognostic Value of Lymphocyte-Activation Gene 3 (LAG3) in Cancer: A Meta-Analysis, Frontiers in oncology, 9 (2019) 1040. 
[24] H.A. Jensen, H.B. Yourish, R.P. Bunaciu, J.D. Varner, A. Yen, Induced myelomonocytic differentiation in leukemia cells is accompanied by noncanonical transcription factor expression, FEBS open bio, 5 (2015) 789-800.

[25] B. Kovacic, D. Stoiber, R. Moriggl, E. Weisz, R.G. Ott, R. Kreibich, D.E. Levy, H. Beug, M. Freissmuth, V. Sexl, STAT1 acts as a tumor promoter for leukemia development, Cancer cell, 10 (2006) 77-87.

[26] V. Gouilleux-Gruart, F. Gouilleux, C. Desaint, J.F. Claisse, J.C. Capiod, J. Delobel, R. WeberNordt, I. Dusanter-Fourt, F. Dreyfus, B. Groner, L. Prin, STAT-related transcription factors are constitutively activated in peripheral blood cells from acute leukemia patients, Blood, 87 (1996) 1692-1697.

[27] R.M. Weber-Nordt, C. Egen, J. Wehinger, W. Ludwig, V. Gouilleux-Gruart, R. Mertelsmann, J. Finke, Constitutive activation of STAT proteins in primary lymphoid and myeloid leukemia cells and in Epstein-Barr virus (EBV)-related lymphoma cell lines, Blood, 88 (1996) 809-816.

[28] H.A. Bruns, M.H. Kaplan, The role of constitutively active Stat6 in leukemia and lymphoma, Critical reviews in oncology/hematology, 57 (2006) 245-253.

[29] B.H. Li, X.Z. Yang, P.D. Li, Q. Yuan, X.H. Liu, J. Yuan, W.J. Zhang, IL-4/Stat6 activities correlate with apoptosis and metastasis in colon cancer cells, Biochemical and biophysical research communications, 369 (2008) 554-560.

[30] N. Carlesso, D.A. Frank, J.D. Griffin, Tyrosyl phosphorylation and DNA binding activity of signal transducers and activators of transcription (STAT) proteins in hematopoietic cell lines transformed by $\mathrm{Bcr} / \mathrm{Abl}$, The Journal of experimental medicine, 183 (1996) 811-820.

[31] S.K. Chai, G.L. Nichols, P. Rothman, Constitutive activation of JAKs and STATs in BCR-Ablexpressing cell lines and peripheral blood cells derived from leukemic patients, Journal of immunology (Baltimore, Md.: 1950), 159 (1997) 4720-4728.

[32] K. Shuai, J. Halpern, J. ten Hoeve, X. Rao, C.L. Sawyers, Constitutive activation of STAT5 by the BCR-ABL oncogene in chronic myelogenous leukemia, Oncogene, 13 (1996) 247-254. 